\title{
Research on the Development Path of Integrated Innovation between Tourism and Cultural Creative Industry-Taking Changzhou Eco-Cultural Tourism Area as an Example
}

\author{
Min Zhang \\ School of Economics and Commerce, South China University of Technology, Guangzhou, China \\ Email:vvinzm@163.com
}

How to cite this paper: Zhang, $M$ (2019) Research on the Development Path of Integrated Innovation between Tourism and Cultural Creative Industry-Taking Changzhou Eco-Cultural Tourism Area as an Example. American Journal of Industrial and Business Management, 9, 72-81.

https://doi.org/10.4236/ajibm.2019.91006

Received: December 24, 2018

Accepted: January 8, 2019

Published: January 11, 2019

Copyright $\odot 2019$ by author(s) and Scientific Research Publishing Inc. This work is licensed under the Creative Commons Attribution International License (CC BY 4.0).

http://creativecommons.org/licenses/by/4.0/

\begin{abstract}
With the improvement and promotion of people's living standards, the rapid development of cultural creative industry and the increase of tourism demand, cultural creative tourism has become a new type of industry, and the integration of tourism and cultural creative industry has become an inevitable trend. Based on the analysis of the current situation of tourism development and the integration development of tourism and cultural creative industry in Changzhou, this paper finds that there are some problems in tourist areas, such as insufficient embodiment of cultural creative elements, not prominent characteristics of tourism and cultural creative integration etc.; therefore it puts forward the path of integration and innovation between tourism and cultural creative industry in Changzhou eco-cultural tourism area. That is, optimizing the spatial pattern and perfecting the functional zoning, reshaping the old scenery around the core theme, developing the characteristic resources and building the flagship project, creating the creative environment and encouraging the innovation and entrepreneurship.
\end{abstract}

\section{Keywords}

Tourism Industry, Cultural Creative Industry, Integrated Innovation Path, Changzhou Eco-Cultural Tourism Area

\section{Introduction}

Under the background of knowledge economy, the role of cultural creative industry in economic development is becoming more and more prominent. As a new industrial form, the development of cultural creative industry is an impor- 
tant way to improve core competitiveness and soft power. With the continuous improvement of consumption level, the demand for spiritual and cultural consumption of Chinese residents is increasing, but the supply of domestic cultural consumption market obviously lags behind the demand of cultural consumption [1]. From the perspective of cultural power in our country, "speeding up the development of cultural industry, promoting cultural industry as the pillar industry of national economy" is clearly put forward, and from the actual development of various regions, the development of cultural industry will be innovation-driven industrial upgrading and transformation, which is conducive to the transformation of old cities, resource development and tourism attractiveness.

Changzhou eco-cultural tourism area is located in Guangzhou Huangpu District Changzhou island; the region is rich in natural and human resources, with more than 20 attractions. Relying on rich historical cultural resources and good ecotourism resources, tourism area promotes the integration and development of tourism and cultural creative industry, which makes it easier to form industrial synergies, and enhance regional competitiveness. Therefore, this paper will explore how Changzhou eco-cultural tourism area can integrate the cultural creative industry and tourism, change its single dependence on its resource advantages of the development model, and increase the cultural content of its tourism resources. This research has certain theoretical and practical significance. At the theoretical level, based on the perspective of industrial integration, this paper takes tourism area as the specific research object, attempts to explore the path of integration between tourism and cultural creative industry, broadens the research perspective of the cultural tourism creative industry integration innovation, and enriches tourism and cultural creative industry related theory of fusion. At the practical level, the exploration of the integrated innovation path of tourism and cultural creative industry provides guidance for the integration and innovation development of cultural creative tourism in the Changzhou eco-cultural tourism area, and promotes the sustainable development of cultural creative tourism in the tourism area.

The article is organized of six parts, including introduction, literature review, tourism and cultural creative industry integration development situation of Changzhou eco-cultural tourism area, tourism and cultural creative industry integration development problems of Changzhou eco-cultural tourism area, tourism and cultural creative industry integration innovation development path of Changzhou eco-cultural tourism area, conclusion and prospect.

\section{Literature Review}

With the rapid development of tourism, culture as the internal core of tourism, cultural creative e tourism has become a new form of industry. More and more scholars pay attention to the integration of the two industries. At present, domestic and foreign scholars have different emphases on the integration of tourism industry and cultural creative industry. The research of foreign scholars mainly focuses on the interaction between the two major industries, such as Smith studied the influence of tourism on traditional culture from the angle of 
sociology and anthropology. Valene Smith and other scholars studied the process of cultural creativity and tourism integration. Adrian Bull studied the impact of cultural creativity on the tourism industry. Yuko Aoyama believed that the rapid development of tourism economy was due in large part to the rise of cultural creative industry.

The research of domestic scholars is more specific, mainly focused on basic theory, path, dynamic mechanism, development mode and so on. Among them, many scholars have carried on the concrete research to the two major industry integration path. La Mingying discussed the development strategy and path of cultural and tourism integration in ethnic areas, providing reference for the development of tourism in ethnic areas [2]. Li Fangfang, Hong Xiafang analyzed the dynamic mechanism of the development of Nanchang cultural creative tourism industry, combined with the analysis results, from resources and Consumption and government and other aspects to put forward Nanchang cultural creative tourism industry development path [3]. Liang Aiwen conducted in-depth study and analysis of Yunnan Dehong Autonomous Prefecture to study the path of developing national cultural tourism creative industry in ethnic areas [4]. Zhu Qijiu, Qian Jing analyzed and studied the four paths of the integrated development of Beijing urban tourism, ecotourism and cultural creative industry, compared the advantages and disadvantages of different paths, and put forward some suggestions for path selection [5]. Zhang Zuqun et al. based on the analysis of the integration mode of tourism and cultural creative industry, proposed the integration path of popular science tourism and ecotourism line, relying on large-scale conference or exhibition activities to carry out exhibition tourism, or relying on cultural industry creative park to carry out industrial tourism [6]. On the basis of discussing the integrated development path of cultural creative industry and related industries, Hua Jian put forward that in the integrated development of cultural creative tourism, the emphasis was on developing the humanistic connotation of various types of tourism projects, which was creating the intellectual core of tourism charm, rich contents, pluralistic subject and dynamic development framework, mainly including industrial subjects, creative content, service platform, foster brand, spatial layout and other contents [7].

In general, domestic and foreign scholars have not yet formed a systematic study on the integration of tourism industry and cultural creative industry, and it is relatively rare to study the mechanism, path and mode of the integration of culture tourism industry in a certain region. In particular, the research on the integration path of tourism industry and cultural creative industry is even less. There are few studies on the path of a certain region or a certain field, and the general applicability is not strong.

\section{Tourism and Cultural Creative Industry Integration Development Situation of Changzhou Eco-Cultural Tourism Area}

Changzhou eco-cultural tourism area includes two districts of Changzhou and 
Shenjing, which are rich in tourism resources and profound cultural heritage. There are Huangpu Military Academy, Sun Yat-sen's former residence, the cemetery of the fallen in battle, the Northern Expedition monument, Huangpu Park, Persia tower, big wave ground fort and other attractions. Shenjing has a large number of ancient residential and other characteristic buildings, also has Changzhou powder and other local specialties, deep well roast goose, Huangpu eggs, to create Changzhou cultural creative tourism new business card. But in general, Changzhou island tourism and cultural creative industry integration degree is not high, to be further excavated. At present, the integration of Changzhou island tourism and cultural creative industry is mainly reflected in tourism commodities, creative shops, specialty farm farms, characteristic cultural festivals and so on. Tourism souvenirs and handicrafts with the theme of military culture are an important part of Changzhou island tourism commodities, such as teacups, kettles, costumes, accessories, postcards and so on. The use of cultural creative elements makes Changzhou island tourism commodities different from other tourism destinations, but the phenomenon of homogenization of tourism commodities on the island cannot be ignored. "Slow Island Station", agricultural creative theme park and other leisure creative shops have become a major feature of the integration of Changzhou island tourism and cultural creativity. Dragon boat racing, "Golden Flower Birthday", Night parking wish lamp and other special cultural festivals add local characteristics for Changzhou island tourism, but these are mainly based on the participation of local residents. There are some limitations in the interactive experience of tourists, and the integrated development of tourism and cultural creative industry has yet to be further improved.

\section{Tourism and Cultural Creative Industry Integration Development Problems of Changzhou Eco-Cultural Tourism Area}

As a new form of industry, cultural creative tourism has been developed rapidly, which has further promoted the integrated development of tourism industry and cultural creative industry, and has also become a new driving force for the development of destination tourism. However, the development of cultural creative tourism in the Changzhou eco-cultural tourism area is relatively slow, except for a few innovative commodities and creative farms. Generally speaking, there are many problems in the integration of tourism and cultural creative industry in Changzhou eco-cultural tourism area at present, which are mainly manifested in the following three aspects.

\subsection{Lack of Cultural and Creative Elements in the Tourism Area}

At present, there is a lack of cultural creative elements in the Changzhou eco-cultural tourism area, and in addition to a few creative tourist shops, there are few local characteristics or elements with cultural creativity in the region. 
There is a lack of unified planning in tourism areas, such as road traffic, scenic spots and other marking system design are simple, which are lack of local cultural characteristics and creativity. In the internal planning of various tourist attractions also did not melt into the corresponding elements of the text, such as leisure promenade, garbage bins and other design are too simple, have no characteristics. Most of the souvenir shops catering accommodation in the tourism area are run and managed by the local residents, and most of them are directly transformed from residential buildings, lack of unified planning, resulting in a low level of style and homogenization of serious phenomenon, and the application of cultural creative elements is even less. Therefore, on the whole, whether it is the marking system and other infrastructure, catering, accommodation, shopping and other supporting facilities, or dragon boat racing and other local folk activities, which are less integrated with cultural creative elements, did not form a unified cultural creative logo or brand.

\subsection{The Integration Characteristics of Tourism and Cultural Creativity Are Not Prominent}

The current tourism activities are mainly based on the visit of Huangpu Military Academy and other cultural resources, leisure excursions in the ancient village of Shenjing, watersports at the marina and cycling around the island in Changzhou eco-cultural tourism area. However, the existing tourism activities have less local characteristics and a weaker sense of participation, and there is a lack of characteristic representative tourism activities in the whole tourism area, which also leads to the integration of tourism and cultural creative industry tourism projects are less and features are not prominent. Local cultural folklore, such as Huangpu Military academy, Shenjing ancient village, dragon boat race, the life of fishermen along the river and so on, has not been fully excavated and utilized. In addition, because of the lack of unity of tourism planning in tourism area and the participation of local residents, many problems have also made the development of cultural creative tourism in Changzhou eco-cultural tourism area relatively slow, and there is no characteristic creative tourism products. Generally speaking, at present, Changzhou eco-cultural tourism area lacks the characteristics of cultural creative tourism products, and the integration of tourism and cultural creativity is not prominent.

\subsection{The Integration Atmosphere of Tourism and Cultural Creativity Is Not Strong}

At present, from the aspects of planning, facilities and services, the integrated development atmosphere of Changzhou island cultural creative tourism is insufficient. First of all, from the master plan of Changzhou island, the trend of cultural creative tourism integration and development is not obvious. Changzhou island tourism development mainly relies on the old site of Huangpu Military Academy and other military cultural themes, for cultural creativity and other emerging elements into the tourism development is insufficient thinking, long-term 
planning is not enough. For example, in present planning mainly infrastructure to upgrade, only limited to the shallow level of transformation to meet the demand, did not consider the cultural and other creative elements fully integrated into it. Secondly, from the current Changzhou island tourism facilities, tourism and cultural creativity integration is not enough. No matter transportation, sign, or accommodation, entertainment, tourist shops, tourist service centers and other supporting facilities, are mainly to meet the most basic needs. There is no unified block and cultural creative brand, and the overall cultural and creative tourism atmosphere is weak. In addition, in terms of service, due to the fact that the majority of local merchants or service personnel are mainly local residents, there is little awareness of tourism development and visitor service with no characteristic service. In general, the integration atmosphere of Changzhou island tourism and cultural creativity is not strong, and the degree of integration is not enough.

\section{Tourism and Cultural Creative Industry Integration Innovation Development Path of Changzhou Eco-Cultural Tourism Area}

\subsection{Optimize the Spatial Pattern and Improve Functional Zoning}

There are many historical and cultural sites in Changzhou eco-cultural tourism area, including military garrison and second and third industrial land. Due to the closeness and particularity of military management, most of the sites are artificially severed and outsiders are difficult to access. The old site of Huangpu Military Academy, the cemetery of the fallen in battle and other important sites are divided or surrounded by Huangpu shipyard, Arsenal, naval camp and other land. The layout is scattered, the overall style of the area is mixed, and the tourist route is not coherent enough to carry out the whole island tour. Because the line traffic is not smooth, which lead to crowd in the individual scenic spot congestion. Therefore, it is imperative to open up the routes between various scenic spots, and optimize the functional pattern of tourist areas to improve the tourist experience, we can start from the following aspects:

Firstly, we must clarify the function of each division in the tourism area, take historical and cultural sites as the main body, Lingnan waters, ancient village style and other resources as auxiliary and the supplement of tourism leisure activities, To form a pattern of tourism products with distinct priorities and various forms. It is mainly divided into historical relic protection zone, lingnan folk custom experience zone, riverside scenery zone and creative recreation zone. The Division of Cultural Relics, natural sightseeing, folklore experience, leisure and entertainment, etc, can better reflect the differences in protection control and planning management of different lots under the premise of overall protection.

Secondly, in order to open the cultural and creative market, we should make clearly the positioning of Changzhou eco-cultural tourism area, which is close to 
Guangzhou University City, Pazhou International Convention and Exhibition Center, as a leisure supporting area around the group. Changzhou island is mostly a vibrant young people, therefore, products that integrate cultural and creative industries with tourism can fit the preferences of their target populations. Therefore, the integration of cultural creative industry and tourism products can meet the preferences of the target population. In order to better connect Changzhou island with target market, the first step is to improve tourism traffic, and actively improve the docking of the surrounding group of transport facilities.

Finally, we should pay attention to the ecological environmental protection in tourism development. Good ecology is the basis for Changzhou island to develop tourism and integrate tourism with cultural and creative industries, so the key to tourism development is ecological protection. At the same time, we should develop historical relics from the perspective of protecting them and keep their original appearance and surrounding buildings.

\subsection{Around the Core Theme and Reshape the Old Landscape}

Around the core theme of "modern revolutionary history and culture", to create the whole island's overall landscape, we can start from the following points: First of all, the unified visual recognition system of each division, including marking system, scenic spot, tourist souvenirs, which are unified use of the same style. The concept of historical stories and patriotism education is incorporated into visual expression in a more vivid and lively form, such as making historical stories into cartoons and fully mobilizing the interest of young tourists in understanding history. Secondly, in the construction of scenic spots to increase the green belt, interspersed with cultural sculpture, graffiti art wall, cultural leisure promenade and other areas, increase the range of recreational activities for tourists, increase the fun and experience, and to avoid tourists too concentrated in the museum area. Thirdly, in today's tourism product homogenization is more serious, the innovation and design of tourism products is not only an important process to improve the added value of the industry, but also a key link to promote the integration between industries, as well as the core link of the cultural and creative industry. The innovation of tourism products can make tourists feel brand-new about the scenic spot, and new forms and business forms can take an advantageous position in the market. For example, Changzhou island can develop diversified business forms around historical and cultural themes, including historical and cultural homestay, coffee shop, book bar, etc.

\subsection{Develop Characteristic Resources and Build Flagship Projects}

There are many cultural and natural resources in Changzhou eco-cultural tourism area, which can build the flagship project of tourism characteristics from the aspects of military cultural experience, creative commodity development and characteristic festival experience. At the same time, the integration of cultural 
creative elements into the development of tourism projects, which can help stimulate new forms of products and services, help to promote business innovation and industrial transformation and upgrading, thus enhancing the attractiveness of tourist areas. Relying on the special tourism resources in the tourism area, with the help of expanding experience, tourism goods, special festivals and other ways, cultural creative elements can be integrated into it, so as to create a special flagship project of Changzhou eco-cultural tourism area.

On the one hand, in the historical and cultural experience zone, we can carry out military culture expansion training, research summer camp and other tourism activities rely on the characteristics of military culture such as Huangpu Military Academy Museum and Huangpu Park for the youth and parent-child market. Through in-depth mining and use of military cultural resources, in the development of training and summer camp projects, pay attention to the refinement and penetration of cultural connotations, with military cultural creativity with the participation of tourists, increase the sense of participation and presence of tourists, thus driving the activation and utilization of cultural resources, and promote the integration and development of tourism and military cultural creativity. On the other hand, from the perspective of cultural creativity, according to the local characteristics, abstract extraction of the classic characteristics of the "theme" and "symbolic" tourism commodities, to create a "Changzhou gifts" series of tourism commodities. To promote the development of cultural and creative tourism in the region with the characteristics of innovative tourism commodities. For example, relying on the Huangpu Military Academy Museum, Sun Yat-sen's former residence and other characteristics of military cultural tourism resources, to create a "salute" gifts, including Huangpu Military Academy miniature model, printed with Huangpu Military Academy logo postcards, costumes, etc. Relying on the tourist area in the deep well burning goose, Huangpu eggs and other soil products to create "agricultural" gifts. Based on the dragon boat racing, three-dimensional bead embroidery and other local folklore, to create "etiquette" gifts. These three together constitute the "Changzhou gifts" series of cultural creative tourism products.

\subsection{Create Cultural Creative Environment and Encourage Innovation Entrepreneurship}

At present, the development of cultural creative tourism in Changzhou eco-cultural tourism area is slow, and the environment of tourism and cultural creative industry integrated development needs to be further improved. In order to promote the integrated development of tourism and cultural creative industry, we should combine creative culture and pay attention to the construction of the overall cultural creative tourism environment. We can start from three aspects of planning, facilities and services to enhance the atmosphere of cultural creative tourism integration and development in tourism areas.

First of all, in the development of tourism area planning should pay attention to the integrated development of tourism and cultural creative industry, make 
cultural creative tourism as an important part of the future development of tourism areas. In the planning, we can propose the introduction of special creative enterprises or attract young entrepreneurs to start a business in tourism areas, such as innovative cafes, literary bookstores, military cultural theme homestay, etc., to encourage innovation and entrepreneurship and lay the foundation for the development of cultural creative tourism. Secondly, from the road traffic, scenic spots signage, tourism shops, tourist service centers and so on, we can unified design style and pay attention to the integration of cultural and creative elements, to create Changzhou island cultural creative brand and improve the atmosphere of the entire tourism area. Finally, in terms of services, a management association composed of scenic spots and community residents has been set up to carry out corresponding service training on a regular basis to improve the service awareness of service personnel in the district. From the overall comprehensive improvement of the tourism environment, while combining cultural and creative elements, to enhance the atmosphere of tourism and cultural creative industry integration innovation in Changzhou eco-cultural tourism area.

\section{Conclusion and Prospect}

On the basis of reviewing the research on the integration of tourism and cultural creative industry, this paper analyzes the current situation and existing problems of the integration innovation of tourism and cultural creative industry in Changzhou eco-cultural tourism area, and puts forward integration innovative development path of the tourism and cultural creative industry from four aspects, including optimizing the spatial pattern and perfecting the functional zoning, reshaping the old scenery around the core theme, developing the characteristic resources and building the flagship project, creating the creative environment and encouraging the innovation and entrepreneurship.

Based on the perspective of industrial integration, this study makes an in-depth analysis of the development path of tourism and cultural creative industry integration and innovation combined with specific cases. However, due to the limited research ability of the author, this study can further expand at these levels. On the one hand, the scope of case selection can be expanded to carry out a comparative study. On the other hand, the study can explore the development path of integrated innovation under different cultural creative tourism modes.

\section{Conflicts of Interest}

The author declares no conflicts of interest regarding the publication of this paper.

\section{References}

[1] Lu, H. (2015) Research on Problems and Countermeasures of Cultural Consump- 
tion in China. Economic BBS, No. 2, 84-88.

[2] La, M.Y. (2011) Discussion on Strategies and Paths for Integrated Development of Culture and Tourism in Ethnic Areas of Western Sichuan Plateau. Journal of Southwest Minzu University (Humanities and Social Sciences Edition), 32, 137-140.

[3] Li, F.F. and Hong, X.F. (2012) Dynamic Mechanism and Realization Approach for the Development of Nanchang Cultural and Creative Tourism Industry. Technological Development of Enterprise, No. 31, 87-90.

[4] Liang, A.W. (2012) Three-Dimensional Path for the Development of Ethnic Cultural Tourism Creative Industry in Ethnic Regions-A Case Study of Dehong Dai and Jingpo Autonomous Prefecture. Heilongjiang National Series, No. 3, 66-71.

[5] Zhu, Q.J. and Qian, J. (2013) Integration Path Selection of Urban Agriculture, Ecological Tourism and Cultural and Creative Industry. Journal of Anhui Agricultural Sciences, No. 1, 167-169.

[6] Zhang, Z.Q. (2013) Integration of Tourism and Cultural Creative Industry: Theory, Mode and Path. Beijing Studies 2013: Culture, Industry and Space, 12.

[7] Hua, J. (2011) On Five Modes of Linkage Development between Cultural Industry and Tourism. Dongyue Tribune, 32, 98-102. 